\title{
Management of Infected Nonunion of the Forearm by the Masquelet Technique
}

\author{
Shabir A Dhar ${ }^{1}$, Tahir A Dar², Naseer A Mir ${ }^{3}$
}

\begin{abstract}
Purpose: Infected nonunion of the forearm bones is a challenge for the orthopedic surgeon on several fronts. The forearm itself is unique as the difficulties include the relation between restoration of shaft length with the anatomy and long-term functional outcome of adjacent joints, and the risk of elbow and wrist stiffness related to prolonged immobilization. The problem of infection is complex due to the presence of bone necrosis, segmental bone loss, sinus tract formation, fracture instability, and scar adhesion of the soft tissues. The ideal management method for these situations is still debated.

Materials and methods: We used the two-stage-induced membrane technique devised by Alain Masquelet for the management of these infected nonunion of 12 forearm bones.

Results: All 12 bones united uneventfully. The bones united in a period ranging from 6 to 12 months with a mean of 7.8 months.

Conclusion: Our results show that this technique addresses several of the challenges pertinent to the forearm nonunion simultaneously and results are uniformly predictable.

Keywords: Bone grafting, Infected nonunion, Masquelet technique.

Strategies in Trauma and Limb Reconstruction (2019): 10.5005/jp-journals-10080-1411
\end{abstract}

\section{INTRODUCTION}

The surgical treatment of diaphyseal forearm fracture nonunions remains a therapeutic challenge for orthopedic trauma surgeons. Key to success in the management of these demanding conditions is to develop a comprehensive treatment concept which considers the forearm and its adjacent joints, the elbow, and wrist, as a complex functional unit. ${ }^{1,2}$ Nonunions of the radius and ulna shaft cause a severe anatomic and functional impairment, related to disturbance of the interosseous membrane and dysfunction of the adjacent joints, elbow, and wrist. ${ }^{3-6}$ Infection complicates the nonunion significantly. Infected nonunion of the forearm is relatively uncommon. The problem is complex due to the presence of bone necrosis, segmental bone loss, sinus tract formation, fracture instability, and scar adhesion of the soft tissues. ${ }^{7,8}$

There have been extensive developments in the reconstruction of defects including (1) distraction osteogenesis, (2) structural auto/allografts, (3) titanium cages and cancellous autograft, (4) polymeric membranes, and (5) free microvascular fibula transplant.

French surgeon Alain-Charles Masquelet developed the Masquelet technique which involves a staged procedure in which a temporary skeletal stabilization is paired with implantation of an antibiotic spacer and left in place for 6-8 weeks, during which time, a "pseudomembrane" forms around the cement spacer. Addition of antibiotics, theoretically, increases the chance of eradication of infection. During the second stage of the procedure, the pseudomembrane is incised, the antibiotic spacer removed, and the bone graft is placed. ${ }^{9-11}$

We used the Masquelet technique in 12 infected forearm nonunions where the defects post-debridement ranged from 3.5 to $7 \mathrm{~cm}$. This paper presents the results and complications of these 12 cases.

\author{
${ }^{1-3}$ SKIMS Medical College and Hospital, Bemina, Srinagar, Jammu and \\ Kashmir, India \\ Corresponding Author: Shabir A Dhar, SKIMS Medical College and \\ Hospital, Bemina, Srinagar, Jammu and Kashmir, India, Phone: +91 \\ 9419489933, e-mail: shabirdhar@yahoo.co.in \\ How to cite this article: Dhar SA, Dar TA, Mir NA. Management of \\ Infected Nonunion of the Forearm by the Masquelet Technique. \\ Strategies Trauma Limb Reconstr 2019;14(1):1-5. \\ Source of support: Nil \\ Conflict of interest: None
}

\section{Materials and Methods}

\section{Surgical Technique}

The infected area was exposed and the hardware removed. The dead and devitalized bone was debrided until bleeding bone with punctate bleeding was exposed Paprika sign. All bone ends were made transverse. The unhealthy soft tissue was removed along with sinus tracts. The defect was stabilized by a plate and screws. The initial five cases were stabilized by conventional dynamic compression plates while we used locking plates in the last seven cases. We attempted to get a six cortex purchase on both sides of the fracture in all cases but had to compromise in three cases where the distal fixation was restricted to four cortices due to the short remaining length of the bony fragment. This was the main reason that we shifted to locking plates in the latter half of the series. In cases with any kind of doubt about the clearance of the infection, we repeated Gram staining during the procedure to ensure proper debridement. The antibiotic cement molded in the shape of the defect was placed in the gap with some degree of wrap over the debrided bone ends. The wound was carefully closed over the cement and the plate (Figs 1 to 4 ).

(O) The Author(s). 2019Open Access This article is distributed under the terms of the Creative Commons Attribution 4.0 International License (https://creativecommons. org/licenses/by-nc/4.0/), which permits unrestricted use, distribution, and non-commercial reproduction in any medium, provided you give appropriate credit to the original author(s) and the source, provide a link to the Creative Commons license, and indicate if changes were made. The Creative Commons Public Domain Dedication waiver (http://creativecommons.org/publicdomain/zero/1.0/) applies to the data made available in this article, unless otherwise stated. 


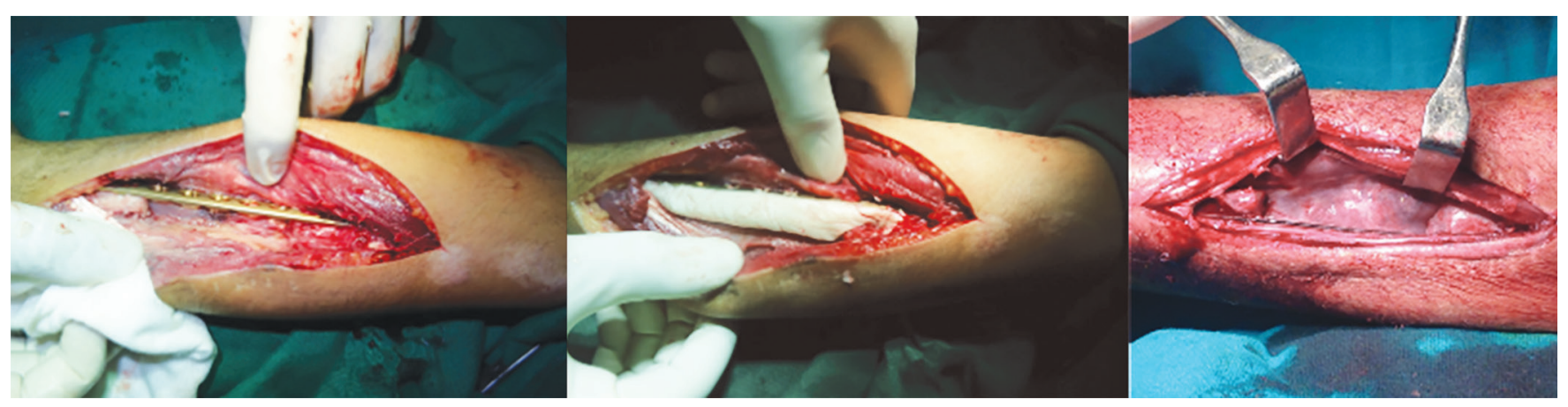

Fig. 1: Debridement with plating. Cement has been placed in the defect. The Masquelet membrane after cement removal

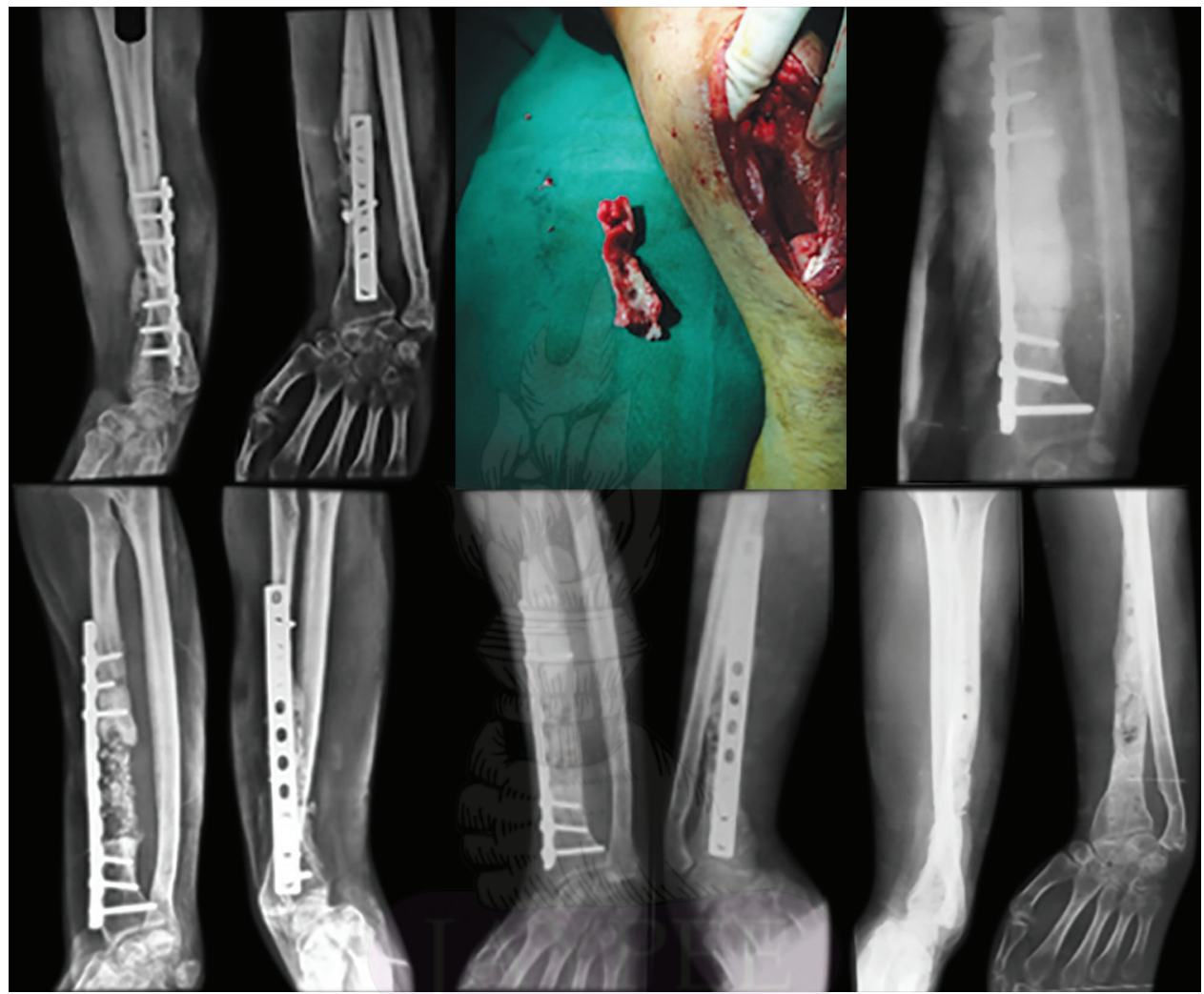

Fig. 2: Infected nonunion of the radius. The plate was removed and the sequestrated fragment was removed. Cement placed in the defect. Initial postoperative radiograph followed by union. Hardware was removed at 2 years follow-up. The patient did not agree to a procedure for the distal radioulnar joint as his hand function was good

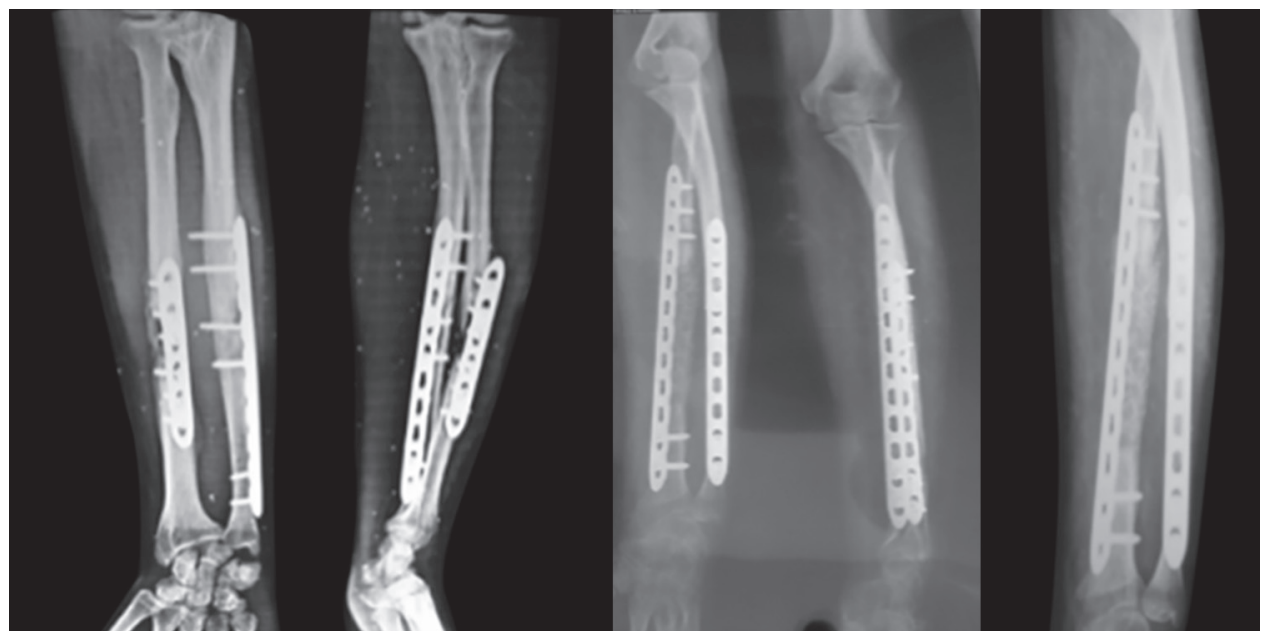

Fig. 3: Infected nonunion of the radius. The radiograph of the postoperative phase after the second stage bone grafting. Union at 6 months

2 Strategies in Trauma and Limb Reconstruction, Volume 14 Issue 1 (January-April 2019)



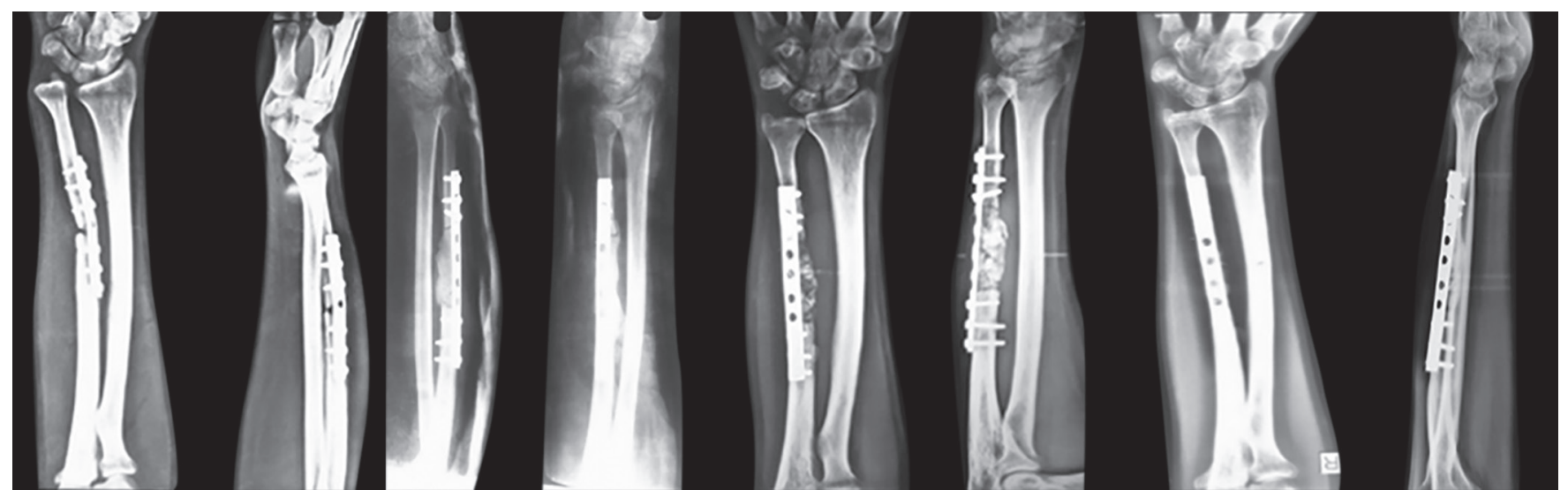

Fig. 4: Infected nonunion of the ulna. Cement placement with fixation. Grafting followed by union at 1 year follow-up

Six weeks after the first procedure, the cement spacer was removed and the ends of the bone were debrided and decorticated. The cement membrane was carefully preserved elsewhere. The graft obtained from the iliac crest was morsellized and placed in the gap. The soft tissue was carefully closed over the graft and the biological membrane creating a closed biological chamber.

Postoperatively, we put all patients on antibiotics based on the culture report, which was changed if the intraoperative material that had been sent for culture grew something else. The antibiotic was continued for 6 weeks.

The patient was placed in a splint for 6 weeks with a careful range of motion being instituted after 2 weeks. Radiological follow-up was done 2 monthly for 6 months and thereafter on a monthly basis.

\section{Results}

Twelve cases were taken up for study. There were 11 males and 1 female. The average age of the patients ranged from 19 to 56 with an average of 37.91 years. The right forearm was involved in seven cases and the left one in five cases. The duration of the infected nonunion ranged from 6 to 18 months with an average of 10.25 months. The culture was obtained from the tissue around the nonunion site in all cases by ultrasound-guided aspiration. The culture grew Staphylococcus aureus in six cases, Escherichia coli in four cases, Klebsiella in one case, and one case showed a mixed growth. According to the sensitivity report, vancomycin was used with the cement in seven cases and tobramycin in five cases. In all the cases, the hardware was removed during the first stage and extensive debridement was done. All cases were fixed at the time of debridement with plates. The defect created ranged from 3.5 to $7 \mathrm{~cm}$ with a mean defect of $5 \mathrm{~cm}$. The range of motion improved in all the cases with the wrist flexion ranging from $40^{\circ}$ to $60^{\circ}$ and the wrist extension ranging from $45^{\circ}$ to $60^{\circ}$ at the final follow-up. The range of pronation ranged from $50^{\circ}$ to $85^{\circ}$ and the pronation from $60^{\circ}$ to $85^{\circ}$.

All patients went on to uneventful union. As there are no clearly defined parameters of union in the Masquelet method, we defined union as a stage when two radiologists and two orthopedic surgeons (apart from the operating surgeon) agreed on the radiograph having reached a stage of union. The bones united in a period ranging from 6 to 12 months with a mean of 7.8 months. At present, the follow-up of our first case is more than 4 years and none of the cases has a follow-up of less than 1 year (Table 1).

\section{Discussion}

Forearm nonunions are uncommon but severely disabling and challenging to treat. ${ }^{12}$ Treatment of diaphyseal forearm nonunions differs from that of other type of diaphyseal nonunions because of the intimate relationship between the radius and the ulna and their reciprocal movement. Other limiting aspects of this particular anatomic location include the relation between restoration of shaft length with the anatomy and long-term functional outcome of adjacent joints, and the risk of elbow and wrist stiffness related to prolonged immobilization. The reported outcomes are moderate at best. $^{13}$

Motor vehicle trauma and injuries sustained in various conflicts are increasing. A high proportion of these injuries will be associated with environmental foreign body and bacterial contamination. Consequently, the management of these injuries is difficult and is still an evolving science.

Nonunion in the presence of infection complicates the management in several ways. The presence of bone necrosis and sequestrae, segmental bone loss, sinus tract formation, fracture instability, soft tissue compromise, and scar adhesion of the soft tissues make management even more difficult. ${ }^{8}$

The prerequisite for the management of any infected nonunion is debridement and excision of infected tissues. This has to be combined with prior restoration of a vascular soft tissue envelope. ${ }^{12,14-16}$

Intramedullary nailing has been recommended as a treatment method for nonunion despite $7 \%$ nonunion rates reported for primary nailing. ${ }^{17}$ Weiland has recommended the use of vascularized autografts for the management of bone defects. ${ }^{18}$ Autologous fibular grafting is technically demanding and has potential donor site morbidity, but has a high rate of success. ${ }^{19}$ Jupiter reported $11 \%$ of the development of nonunion of the graft to the host site following compression plating and grafting with iliac crest autograft. ${ }^{20}$ We have used the ilizarov method with success rates in the forearm being lower than other long bone areas. $^{21}$

Traditional bone graft techniques are limited by uncontrollable graft resorption, even when the recipient site is well vascularized. ${ }^{22}$ Masquelet technique uses antibiotic-impregnated cement beads or spacers for local antibiotic administration to the soft tissue bed. In addition, the advantages of inserting such a spacer include maintaining a well-defined void to allow for later placement of graft, providing structural support, offloading the implant, and inducing the formation of a biomembrane. Masquelet and Begue 
Table 1: The clinical parameters of the patients

\begin{tabular}{|c|c|c|c|c|c|c|c|c|c|}
\hline Sno & Age/sex & Side/bone & Culture & $\begin{array}{l}\text { Duration } \\
\text { (minute) }\end{array}$ & $\begin{array}{c}\text { Defect created } \\
(\mathrm{cm})\end{array}$ & $\begin{array}{c}\text { Antibiotic } \\
\text { used }\end{array}$ & $\begin{array}{l}\text { ROM Flex/ext } \\
\text { [wrist] }\end{array}$ & ROM Sup/pron & Union $(m)$ \\
\hline 1 & $28 / \mathrm{M}$ & $\mathrm{R} /$ radius & Staph. & 6 & 4 & Vancomycin & $45-0-50$ & $45-0-80$ & 6 \\
\hline 2 & $36 / M$ & $\mathrm{R} /$ radius & Staph. & 8 & 6 & Vancomycin & $40-0-60$ & $80-0-80$ & 8 \\
\hline 3 & $37 / M$ & L/ulna & Staph. & 12 & 5.5 & Vancomycin & $50-0-55$ & $75-0-80$ & 8 \\
\hline 4 & $19 / M$ & R/ulna & E. coli & 14 & 6 & Tobramycin & $60-0-60$ & $80-0-70$ & 12 \\
\hline 5 & $38 / F$ & L/ulna & E. coli & 6 & 4 & Tobramycin & $60-0-60$ & $60-0-50$ & 6 \\
\hline 6 & $63 / \mathrm{M}$ & $\mathrm{R} /$ radius & Staph. & 7 & 3.5 & Vancomycin & $50-0-55$ & $70-0-65$ & 6 \\
\hline 7 & $42 / M$ & $\mathrm{~L} /$ radius & Klebs. & 18 & 6 & Tobramycin & $50-0-55$ & $75-0-70$ & 9 \\
\hline 8 & $23 / M$ & L/ulna & Mixed & 7 & 6 & Vancomycin & $60-0-60$ & $80-0-80$ & 9 \\
\hline 9 & $31 / M$ & R/ulna & Staph. & 18 & 7 & Vancomycin & $55-0-55$ & $75-0-75$ & 12 \\
\hline 10 & $54 / \mathrm{M}$ & $\mathrm{R} /$ radius & E. coli & 9 & 4 & Tobramycin & $45-0-45$ & $60-0-60$ & 6 \\
\hline 11 & $56 / M$ & R/ulna & Staph & 6 & 4.5 & Vancomycin & $50-0-45$ & $55-0-70$ & 6 \\
\hline 12 & $28 / \mathrm{M}$ & L/ulna & E. coli & 12 & 5 & Tobramycin & $60-0-60$ & $80-0-85$ & 6 \\
\hline
\end{tabular}

proposed that this membrane prevents graft resorption and improves vascularity and corticalization. ${ }^{10}$

It has been described that, after the initial placement of the antibiotic-impregnated spacer, an interval of $4-5$ weeks is needed for the development and maturation of a biologically active membrane that is suitable for grafting. The spacer also maintains the defect and inhibits fibrous ingrowth. ${ }^{11}$

The spacer results in a pseudomembrane, which has been shown, in rabbits, to secrete vascular endothelial growth factor (VEGF), transforming growth factor-B (TGF-B), and BMP-2. This stimulates bone formation. ${ }^{23}$

After debridement, all our cases had a critical-sized defect. A critical-sized defect is defined as the smallest bony defect that does not heal spontaneously and is generally defined as $6 \mathrm{~cm}$. However, it is more logically defined in the context of the bone, with a criticalsized defect defined by multiplying the shaft diameter by $2.0-2.5 .^{24}$

The preferred type of fixation in most cases of pseudoarthrosis is the external fixator. However, this type of fixation does not always provide rigid enough fixation throughout the process of healing and fixation of the radius proximally is an issue as the posterior interosseous nerve is likely to get damaged. Therefore, we used a plate to stabilize the defect and found the results to be good without any persistent and recurrent infection at the time of final follow-up. The use of a tibial nail from the beginning, along with the Masquelet procedure, has been reported. ${ }^{25}$

The graft material used in such cases is of several types. Recently, the reamer irrigator and the aspirator have been used to harvest graft from the femur. However, this graft is dense and can cause irregular union. Currently, the gold standard for graft material is the cancellous graft obtained from the iliac crest. ${ }^{10,26,27}$ This graft provides osteoinductive, osteoconductive, and osteogenic properties. ${ }^{28}$ However, the large volumes of graft material required to fill criticalsized segmental defects lead to an increase in the incidence of comorbidities associated with the harvesting of large amounts of autograft, its exclusive use in these scenarios can often outweigh the benefits. Materials used to help decrease the reliance on autograft are mostly osteoconductive, they can, however, be combined with proteins such as bone morphogenic proteins (BMPs). ${ }^{29,30}$ Complications have been reported with the addition of inductive proteins into graft materials including the need for supraphysiologic concentrations, ossification in adjacent unwanted sites, the inability to control their timing of release, and a potential risk of cancer. ${ }^{31}$ Luo et al. studied the Masquelet technique in seven cases and reported a 100\% union rate. They mentioned that the technique was essentially meant for the lower limb, but produced excellent results in the upper limb too.

In all our cases, we found that we could obtain enough graft from a single iliac crest to fill the defects which ranged from 3.5 to $7 \mathrm{~cm}$. This is easily achieved in the forearm than in other long bones due to the difference in the mass of the bones.

\section{Conclusion}

Infected nonunion of the forearm bones is a difficult problem and the treatment options continue to evolve. The Masquelet procedure is an effective procedure for such situations. On the basis of our findings, we would suggest that it should be the frontline procedure for the management of the infected nonunion of the forearm bones.

\section{References}

1. Rochard MJ, Ruch DS, et al. 3rd: Malunions and nonunions of the forearm. Hand Clin 2007;23:235-243. DOI: 10.1016/j.hcl.2007.02.005.

2. Richards RR. Chronic disorders of the forearm. J Bone Joint Surg Am 1996;78(6):916-930. DOI: 10.2106/00004623-199606000-00017.

3. Schemitsch EH, Richards RR. The effects of malunion on functional outcome after plate fixation of fractures of both bones of the forearm in adults. J Bone Joint Surg Am 1992;74:1068-1078. DOI: 10.2106/00004623-199274070-00014.

4. Hollister AM, Gellman $\mathrm{H}$, et al. The relationship of the interosseous membrane to the axis of rotation of the forearm. Clin Orthop Relat Res 1994;298:272-276. DOI: 10.1097/00003086-199401000-00036.

5. Skahen JR, Palmer AK, et al. The interosseous membrane of the forearm: anatomy and function. J Hand Surg Am 1997;22:981-985. DOI: 10.1016/S0363-5023(97)80036-6.

6. Tarr RR, Garfinkel Al, et al. The effects of angular and rotational deformities of both bones of the forearm. J Bone Joint Surg Am 1984;66:65-70. DOI: 10.2106/00004623-198466010-00010.

7. Prasarn ML, Ouellette EA, et al. Infected nonunions of diaphyseal fractures of the forearm. Arch Orthop Trauma Surg 2010;130(7): 867-873. DOI: 10.1007/s00402-009-1016-4.

8. Ring D, Allende $C$, et al. Ununited diapyseal forearm fractures with segmental defects: plate fixation and autogenous cancellous bone-grafting. J Bone Joint Surg Am 2004;86(11):2440-2445. DOI: 10.2106/00004623-200411000-00013.

9. Ziran NM, Smith WR. The 'Ziran' wrap: reconstruction of critical-sized long bone defects using a fascial autograft and reamer-irrigator-aspirator autograft. Patient Saf Surg 2014;8:40. DOI: 10.1186/s13037-014-0040-7.

10. Masquelet $A C$, Fitoussi $F$, et al. Reconstruction of the long bones by the induced membrane and spongy autograft. Ann Plast Surg 2000;45(3):346-353. 
11. Masquelet AC, Begue T. The concept of induced membrane for reconstruction of long bone defects. Orthop Clin North Am 2010;41(1):27-37. DOI: 10.1016/j.ocl.2009.07.011.

12. Kloen $P$, Buijze GA, et al. Management of forearm nonunions: current concepts. Strat Traum Limb Recon 2012;7:1-11. DOI: 10.1007/s11751011-0125-0.

13. dos Reis FB, Faloppa F, et al. Outcome of diaphyseal forearm fracturenonunions treated by autologous bone grafting and compression plating. Ann Surg Innov Res 2009;3:5. DOI: 10.1186/1750-1164-3-5.

14. Hosny G, Shawky MS. The treatment of infected non union of the tibia by compression-distraction techniques using the ilizarov external fixator. Int orthop 1998;22:298-302. DOI: 10.1007/s002640050264.

15. Garcia-Cimbrelo E, Marti-Gonzalez JC. Circular external fixation in tibial non unions. Clin Orthop 2004;419:65-70. DOI: 10.1097/00003086200402000-00011.

16. Rigal $\mathrm{S}$, Merloz $\mathrm{P}$, et al. Bone transport techniques in post traumatic bone defects. Orthop Traumatol Surg Res 2012;98:103-108. DOI: 10.1016/j.otsr.2011.11.002.

17. Street DM. Intramedullary forearm nailing. Clin Orthop Relat Res 1986;212:219-230. DOI: 10.1097/00003086-198611000-00023.

18. Weiland AJ, Phillips TW, et al. Bone grafts: a radiologic, histologic, and biomechanical model comparing autografts, allografts, and free vascularized bone grafts. Plast Reconstr Surg 1984;74(3):368-379. DOI: 10.1097/00006534-198409000-00006.

19. Mack GR, Lichtman DM, et al. Fibular autografts for distal defects of the radius. J Hand Surg Am 1979;4(6):576-583. DOI: 10.1016/S03635023(79)80011-8.

20. Wei SY, Born CT, et al. Diaphyseal forearm fractures treated with and without bone graft. J Trauma 1999;46(6):1045-1048. DOI: 10.1097/00005373-199906000-00011.

21. Dhar SA, Mir MR, et al. Acute peg in hole docking in the management of infected non-union of long bones. Int Orthop 2008 Aug;32(4): 559-66. DOI: 10.1007/s00264-007-0353-6.

22. Hertel R, Gerber A, et al. Cancellous bone graft for skeletal reconstruction: muscular vs periosteal bed-preliminary report. Injury 1994;25 Suppl 1:A59-A70.
23. Pelissier $\mathrm{P}$, Masquelet $\mathrm{AC}$, et al. Induced membranes secrete growth factors including vascular and osteoconductive factors and could stimulate bone regeneration. J Orthop Res 2004;22(1):73-79. DOI: 10.1016/S0736-0266(03)00165-7.

24. Gugala Z, Lindsey RW, et al. New approaches in the treatment of critical-size segmental defects in long bones. Macromol Symp 2007;253:147-161. DOI: 10.1002/masy.200750722.

25. Apard T, Bigorre N, et al. Two stage reconstruction of the posttraumatic tibia bone loss with nailing. Orthop Traumatol Surg Res 2010;96:549-553. DOI: 10.1016/j.otsr.2010.02.010.

26. Stafford PR, Norris BL. Reamer irrigator aspirator bone graft and bi Masquelet technique for segmental bone defect non union; a review of 25 cases. Injury 2010;41 Suppl 2:72-77. DOI: 10.1016/S00201383(10)70014-0.

27. Karger C, Kishi T, et al. Treatment of posttraumatic bone defects by the induced membrane technique. Orthop Traumatol Surg Res 2012;98:97-102. DOI: 10.1016/j.otsr.2011.11.001.

28. Giannoudis PV, Dinopoulos H, et al. Bone substitutes: an update. Injury 2005;36 Suppl 3:S20-S27. DOI: 10.1016/j.injury.2005.07.029.

29. Govender SM, Csimma CRM, et al. The Bmp-2 Evaluation In Surgery For Tibial Trauma Study G (2002) Recombinant Human Bone Morphogenetic Protein-2 For Treatment Of Open Tibial Fractures: A Prospective, Controlled, Randomized Study Of Four Hundred And Fifty Patients. J Bone Jt Surg Am Vol 2002;84(12):2123-2134. DOI: 10.2106/00004623-200212000-00001.

30. Geiger $\mathrm{F}$, Lorenz $\mathrm{H}$, et al. VEGF producing bone marrow stromal cells (BMSC) enhance vascularization and resorption of a natural coral bone substitute. Bone 2007;41:516-522. DOI: 10.1016/ j.bone.2007.06.018.

31. Christou C, Oliver RA, et al. The Masquelet Technique for Membrane Induction and the Healing of Ovine Critical Sized Segmental Defects. PLoS One 2014;9(12):e114122. DOI: 10.1371/journal. pone. 0114122 .

32. Luo TD. Management of recalcitrant osteomyelitis and segmental bone loss of the forearm with the Masquelet technique. J Hand Surg Eur Vol 2016 May 26. 